\title{
Storage tank materials for biodiesel blends; the analysis of fuel property changes
}

\author{
Leily Nurul Komariah ${ }^{1,2^{*}}$, Marwani ${ }^{1}$, Sucia Aprisah ${ }^{2}$, Yangia S.L Rosa ${ }^{2}$ \\ ${ }^{1}$ Department of Chemical Engineering Universitas Sriwijaya, 30139 Palembang, Indonesia \\ ${ }^{2}$ Renewable Energy Laboratory Universitas Sriwijaya, 30662 Inderalaya, Indonesia
}

\begin{abstract}
Fuel stability is one of major problem in biodiesel application. Some of the physical properties of biodiesel are commonly changed during storage. The change in physico-chemical properties is strongly correlated to the stability of the fuel. This study is objected to observe the potential materials for biodiesel storage. The test was conducted in three kinds of tank materials, such as glass, HDPE, and stainless steel. The fuel properties are monitored in 12 weeks, while the sample was analyzed every week. Biodiesel used is palm oil based. The storage tanks were placed in a confined indoor space with range of temperature 27-34 ${ }^{\circ} \mathrm{C}$. The relative humidity and sunshine duration on the location was also evaluated. The observed properties of the fuel blends were density, viscosity and water content. During 12 weeks of storage, the average density of B20 was changed very slightly in all tanks, while the viscosity was tend to increase sharply, especially in polimerics tank. Water content of B20 was increased by the increase of storage time especially in HDPE tank. In short period of storage, the biodiesel blends is found more stable in glass tank due to its versatility to prohibit oxidation, degradation, and its chemical resistance.
\end{abstract}

\section{Introduction}

Biodiesel has become more attractive as alternative fuel due to its environmental benefits and the fact that it is made from renewable sources. With the soaring price of petroleum-based products, biodiesel is becoming an increasingly affordable option relative to petroleum diesel. As substitute, biodiesel has been promoted to all energy users, such as transportation, industrial, commercial and institutional sectors. Biodiesel is commonly applied in a blend with petroleum diesel oil. A blend is designated by the percentage of biodiesel in the blend. For example: B20 is a fuel containing 80 percent petrodiesel and 20 percent B100.

In Indonesia, the utilization of biodiesel has been mandated as stated in Regulation of Ministry of Energy and Mineral Resources No.32/2008 and No. 23/2013 and No. 26/2015. The permit trading holder of fuel oil in Indonesia are required to blend petrodiesel with biodiesel according to minimal phasing as obliged. Currently, the minimum phasing obligation on biodiesel blends is $20 \%$. It means B20 is already existed in the fuel market of diesel oil particularly in Indonesia.

Biodiesel fuel properties are relatively comparable to diesel engine. Therefore, behind its advantage provided, biodiesel also shows the potential shortcomings problem that need to be solved and anticipated. One of important problem is fuel storage instability. Biodiesel resulted from the production unit may be in good condition, but it can become unacceptable during distribution and storage without proper care and attention. Using biodiesel that does not meet the quality standards may caused engine failure, filter plugging, and adverse tailpipe emissions.

Biodiesel is not always compatible with the existing fuel storage and distribution infrastructure (Knothe 2005), especially in high blending ratio. Many users do not recommend storing biodiesel blends for more than six months. It is strongly related to the low stability of the fuel. So it becomes one of critical problem in biodiesel utilization.

From the various works and research, it has been identified that biodiesel oxidized and degraded faster than diesel oil [1], [2] Some physico-chemical properties are changed during storage. Acid value, density, and kinematic viscosity increase with the increase in storage time of biodiesel as reported by [1-7]. Otherwise, some authors stated that under storage duration, the acid value and flash point temperature of biodiesel are nearest to constant [8-9]. All the effects were observed more in a higher temperature of storage $[7,10]$. The water content of the biodiesel showed increasing trend during storage as reported by [2, 10-11]. Biodiesel is hygroscopic it can absorb atmospheric moisture or pick up water in storage. Hence, water content of biodiesel is increased due to the methyl ester can quickly absorb moisture when storage container possibly opened or contacted with air.

From most of the research results, the fuel properties are still below all the standard values for the whole testing period in storage tanks with lower temperature [7,

\footnotetext{
* Corresponding author: leilynurul@unsri.ac.id
} 
$10,12]$. The testing period is varied from 3 to 52 weeks or under one year.

Biodiesel mostly produced from unsaturated fats contributed from vegetables oil. It tends to oxidize and degrade rapidly. In addition, any previous process that removes the natural antioxidants from the oil (such as bleaching, deodorizing, or distilling) will hasten oxidation. In general, biodiesel will degrade more quickly than petro-diesel. Biodiesel can degrade due to oxidation, contact with water, and/or microbial activity.

Oxidation stability of biodiesel correlates with major fatty acid methyl ester composition i.e., different types of fatty acids provide different degree of unsaturation and long chain saturated factor $[2,13]$. The oxidation of biodiesel can produce various acids or polymers, which, if in high enough concentration, can cause fuel system deposits and lead to filter clogging and fuel system malfunctions [14]. Unsaturated components in biodiesel are more chemically reactive and less stable [15]. The presence of double bond in fatty acid molecule can make a high level of reactivity with the oxygen when exposed to the air during storage [2]. From previous works, it is noted that oxygen exposure, contamination from metals and other radical initiators, water, oxygen and light exposure, and heat could all contribute to degradation of biodiesel quality $[6,16]$.

Most of the tests for neat biodiesel was conducted in existed diesel oil storage tank which is majorly made of metal. Some of other authors conducted some tests of biodiesel in glass storage tank, they concluded that the water content shows no significant effect on the biodiesel storage within 150 days [10]. The biodiesel are commonly stable when it stored in the dark place and without present of light [4]. There are severe effects when the fuel was exposed to daylight and air $[10,16]$. The stability of blends is highly influenced by storage temperature.

One of popular materials for forthcoming storage tank is High Density Poly Ethylene (HDPE). HDPE is a polyethylene thermoplastic made from petroleum. HDPE is known for its large strength-to-density ratio. It is also harder and more opaque and can withstand somewhat higher temperatures $\left(120^{\circ} \mathrm{C} / 248^{\circ} \mathrm{F}\right.$ for short periods). HDPE fuel tank can possibly used for fuel storage due to its versatility. This material is known as good to reduce fuel permeation beside its great chemical resistance. A recent study conducted by Christensen \& L.McCormick, 2014), they reported that biodiesel blends stored in polyethylene fuel tanks were stable for 380 days when held at $23{ }^{\circ} \mathrm{C}$, but production of peroxides and acids was detected when the fuel was stored for 56 days at higher temperature $\left(80^{\circ} \mathrm{C}\right)$. However, the test performing biodiesel blends storage in HDPE and other polymeric materials are still limited.

Most tanks designed to store diesel fuel will store blends of B20 and above with no problem. Many authors reported that under 2016 hours (three months) of storage duration, the effect of degradation was happened in diesel fuel in acceptable ranges [4, 10, 12]. But in practice, it requires some additional considerations due to environmental circumstances. If the fuel stored in higher temperature and humidity it possibly triggering oxidation and further problems like fuel degradation and materials corrosion. Under normal storage conditions diesel fuel can be expected to stay in a useable condition for 12 months or longer at an ambient of $20^{\circ} \mathrm{C}$, and 6-12 months at an ambient temperature higher than $30^{\circ} \mathrm{C}$. Nevertheless, some of guidance stated that biodiesel should be stored at or above $40^{\circ} \mathrm{F}$ considering the cold flow standard. Storage for neat and blended Biodiesel fuels longer than 6 months should have antioxidants blended at point of sale.

The storage stability of biodiesel is a critical issue. For some of practical users, biodiesel shelflife is from four weeks to four months [17]. It is largely dependent of the initial storage stability of the neat form of the fuel [11]. Hence, it is suggested to avoid large storage periods from the storage stage to the dispensing stations. Oxygen exposure, water exposure, light exposure, and heat could all contribute to degradation of fuel quality [16]. As any diesel fuel ages, it can degrade via thermal and oxidative processes to form polymers and acids. This chemical change is promoted by exposure to high temperature and pressure, oxygen, acids, certain metals such as copper and zinc, or combinations of these.

It had been mentioned that the only metallic materials compatible and recommended being used with biodiesel are stainless steel and aluminum [18]. Stainless steel it far being the most compatible with biodiesel. It is compatible with high-percentage biodiesel blends due to its chemical resistance [17].

The fuel storage is majorly carried out outdoors for safety and environmental considerations. Fuel is a flammable materials and its leaks will possibly hazardous. Therefore the type, position, distance and methods of fuel storage handling is specifically regulated.

Storage tanks for a particular fuel are commonly chosen according to the characteristics of that substance. The most expected characteristics from fuel storage is lower build costs and greater chemical resistance. While steel and concrete remain one of the most popular choices for tanks, glass-reinforced plastic, thermoplastic and polyethylene tanks are increasing in popularity. They offer lower build costs and greater chemical resistance.

Table 1. Materials for Storage Tank

\begin{tabular}{|l|l|}
\hline \multicolumn{1}{|c|}{ Type } & \multicolumn{1}{c|}{ Specific Materials } \\
\hline Metals & $\begin{array}{l}\text { Aluminium } \\
\text { Steel (Mild/Carbon Steel) } \\
\text { Stainless Steel }\end{array}$ \\
\hline Concrete & Concrete \\
\hline Elastomer & $\begin{array}{l}\text { Viton, Fluorosilicone, Hifluoer, Fluorocarbon, } \\
\text { Chemraz, Teflon }\end{array}$ \\
\hline Polymer & $\begin{array}{l}\text { Polypropilene, Polethylene (HDPE), } \\
\text { Fluoronated Materials, Nylon }\end{array}$ \\
\hline
\end{tabular}

Biodiesel storage methods are closely similar to conventional diesel storage methods; however, there are some considerations for optimum fuel longevity and purity. Biodiesel blends may commonly stored in existed fuel tank with special treatments or potentially placed in 
a new method of storage with different tank materials and conditions. Due to the nature characteristics of the fuel and its interaction with environment conditions, the new potential materials must be accounted for biodiesel storage especially in specified period (12 weeks). A series of test must be conducted to check the stability of biodiesel blends in polymeric tank storage compared to steel.

\section{Experimental methods}

In this current research, any changes in physico-chemical properties of the B20 was analyzed compared to B0 and B100 on 3 (three) kinds of materials of storage tank such as metal (stainless steel) and polymerics (HDPE and glass). Those tanks were place above the ground in a wide and high ceiling room, with normal temperature. No heating features attached on those tanks.

Biodiesel used in this work is palm oil based, while the petroleum diesel oil used is automotive diesel oil (ADO) or diesel oil grade\#2. The fuel sample was stored in three storage tanks placed in a confined space on a rack upper ground in a big and high ceiling room. The fuel properties was monitored weekly in period of 12 weeks. The samples were analyzed periodically. The properties of fuel sample considered in this study are included density, kinematic viscosity and water content. Environmental parameters observed were temperature, sunshine hours, and reative humidity.

The palm biodiesel used in this study was supplied by PT. Sumiasih Oleochemicals Industry, West Java, Indonesia and petroleum diesel oil was taken from refinery unit III of PT. PERTAMINA, Palembang, Indonesia. The biodiesel used was palm oil based that met standards according to ASTM D613 and SNI 047182-2006.

Table 2. Methods for Fuel Properties Analysis

\begin{tabular}{|l|l|c|}
\hline \multicolumn{1}{|c|}{ Parameters } & \multicolumn{1}{c|}{ Units } & Method \\
\hline Kinematic Viscosity & $\mathrm{cSt}\left(\mathrm{mm}^{2} / \mathrm{s}\right)$ & ASTM D445 \\
\hline Density & $\mathrm{kg} / \mathrm{m} 3$ & ASTM D941 \\
\hline Acid Value & $\mathrm{mg} \mathrm{KOH} / \mathrm{g}$ & ASTM D971 \\
\hline Water Content & $\mathrm{mg} / \mathrm{kg}$ & Karl Fischer \\
\hline Flash Point & ${ }^{\circ} \mathrm{C}$ & ASTM D93-94 \\
\hline Calorific Value & $\mathrm{cal} / \mathrm{gr}$ & ASTM D240 \\
\hline
\end{tabular}

The initial properties of each sample of fuel sample are summarized in Table 3.

Table 3. Initial properties of the fuel samples

\begin{tabular}{|l|l|r|r|r|}
\hline \multicolumn{1}{|c|}{ Property } & \multicolumn{1}{|c|}{ units } & \multicolumn{1}{|c|}{$\begin{array}{c}\text { B0 (Diesel } \\
\text { Oil) }\end{array}$} & \multicolumn{1}{c|}{ B20 } & B100 \\
\hline $\begin{array}{l}\text { Kinematic } \\
\text { Viscosity }\end{array}$ & $\mathrm{mm} 2 / \mathrm{s}$ & 2.798 & 3.112 & 5.142 \\
\hline Density & $\mathrm{g} / \mathrm{mL}$ & 0.825 & 0.831 & 0.868 \\
\hline $\begin{array}{l}\text { Water } \\
\text { Content }\end{array}$ & $\mathrm{mg} / \mathrm{kg}$ & 83.300 & 261.200 & 1644.660 \\
\hline
\end{tabular}

Fuel storage stability then analyzed based on the ability of a fuel to resist changes in its physicochemical characteristics brought by interaction with its environment and the materials of storage tank.

\section{Results and discussion}

In the current work, storage stability of biodiesel blends is represented through the changes in physical properties of the fuel during 12 weeks of storage time.

The fuel density of B20 commonly tend to increased during the storage period. It increased very slightly in all type of tanks. It is quite convincing, due to the neat biodiesel (B100) storage also showed no significant changes in fuel density in 12 weeks of storage time. It was only changed with an average of less than $1 \%$, as shown in Fig 1.

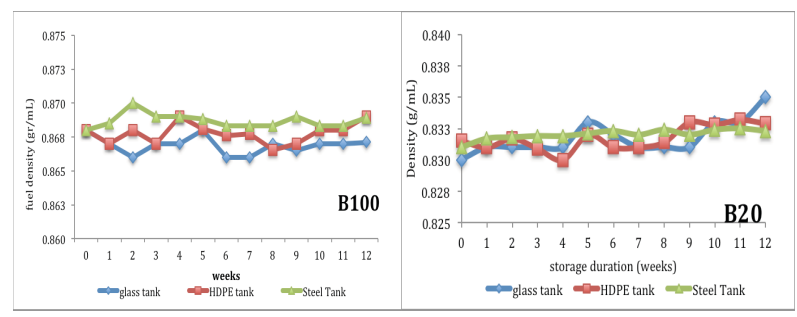

Fig 1. Profile of Density Changes in [a] Biodiesel (B100) and [b] Biodiesel blends (B20)

The increase in density was commonly caused by the formation of oxidation products, that molecularly higher in weight. The slight increase on fuel density was influenced by storage condition that relatively stable. The average ambient temperature around the place of the three storage tanks was recorded between $22-35{ }^{\circ} \mathrm{C}$ as recorded in Fig 2a. In that range of temperature, the effect of oxidation of B20 was not significant. It is in line with the conclusions made by Zakaria et al., (2014), they stated that the oxidation of biodiesel proceed in temperature higher than $40{ }^{\circ} \mathrm{C}$.

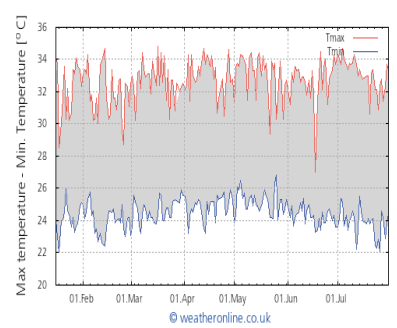

[a] Temperature

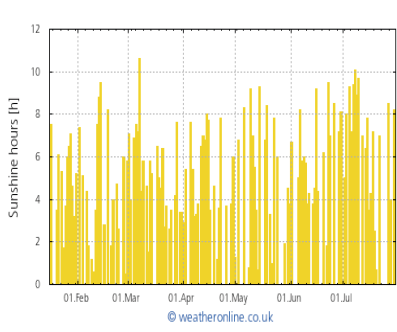

[b] Sunshine hours
Fig 2. Climate Data on Storage Location - Palembang South Sumatera [a] Temperature [b]. Sunshine Hours Source : http://www.weatheronline.co.uk, http://bmkg.go.id

As seen in Fig 1, the density changes of biodiesel blends in glass tank look more prominent than in HDPE and steel tank. It is confirmed that the presence of saturated fatty acid in the fuel stored in glass tank was higher in composition and purity. compared to GDPE and steel tanks. This is probably due to the conditions around the storage tanks were still allow receiving light from electricity lamps and sunlight coming in through 
the windows or ventilators, eventhough those tanks were placed indoor.

The increased in density is commonly linear with an increase in viscosity. In this current work, the viscosity of B20 increased more sharply with the storage time as shown in Fig. 3. The greatest change occurred in B20 was when it stored in the HDPE tank rather than steel tank and glass tank. It is clearly seen that the lowest changes in viscosity was occurred on steel tank, it changed from $3.112 \mathrm{~mm} 2 / \mathrm{s}$ to $3.188 \mathrm{~mm} 2 / \mathrm{s}$. A storage of B20 in glass tank was more stable ini viscocity rather than HDPE tank. In 12 weeks of storage time, the viscosity of B20 in HDPE and glass tank was increased in $3.9 \%$ and $3.7 \%$, respectively. It is also related to the average long duration of sunshine hours at the location of the storage, as presented in Fig. $2 b$.
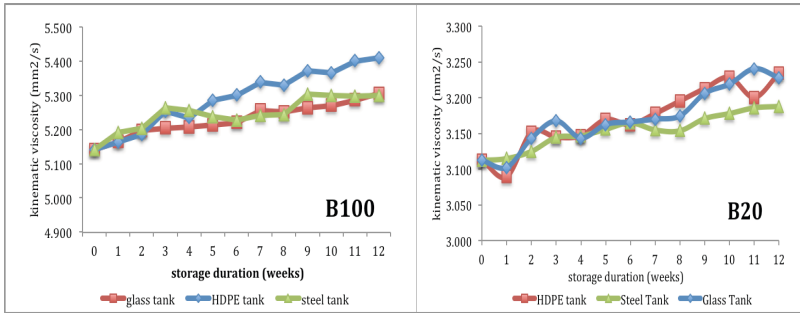

Fig. 3. Profile of Viscosity Changes in [a] Biodiesel (B100) and [b] Biodiesel blends (B20)

The linear regression equation is generated to perform a projection regardings maximum storage time in case of viscosity standard limit as stated in ASTM D975. The maximum viscosity for diesel oil grade \#2 is $4.1 \mathrm{~mm}^{2} / \mathrm{s}$.

Table 3. Projection Maximum Time for Storing B20 under standard of kinematic viscosity

\begin{tabular}{|l|c|c|}
\hline Storage Type & Regression Equation & $\begin{array}{c}\text { Projection Storage } \\
\text { Time Limit [days] }\end{array}$ \\
\hline Glass Tank & $\mathrm{y}=0.0103 \mathrm{x}+3.1099$ & 605 \\
\hline HDPE tank & $\mathrm{y}=0.0105 \mathrm{x}+3.1083$ & 661 \\
\hline Steel Tank & $\mathrm{y}=0.0061 \mathrm{x}+3.1168$ & 1128 \\
\hline
\end{tabular}

As seen on Table 3 , in such a period of 12 weeks or 84 days, the B20 storage will not caused any severe effects on the viscosity of the fuel until specified time limit. Any changes in oil viscosity is attributed as an effect of oxidation. The greater changes occurred in viscosity almost equal to the magnitude effects on oxidation caused during storage. Kinematic viscosity significantly influenced by compound structure that also sensitive to any changes in temperature and light exposure during storage. In a period of storage time, the viscosity of the methyl esters is increased by the formation of more polar, oxygen-containing molecules and also by the formation of oxidized polymeric compounds, possibly leading to the formation of insoluble products [19]. In 12 weeks of storage time, the changes in water content for B20 and B100 were examined and compared. The water content of biodiesel and its blends was significantly increased with increasing storage time as shown in Fig. 4.
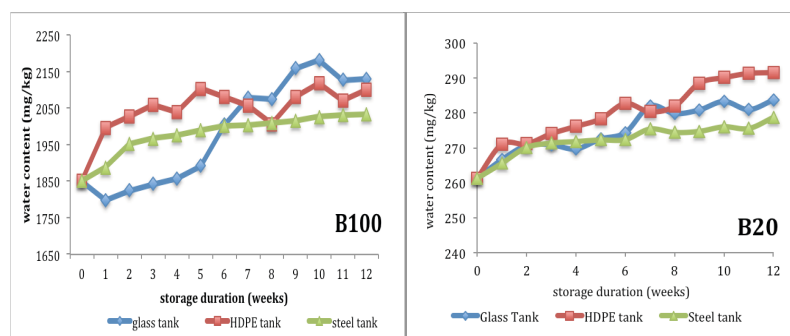

Fig 4. Profile of Water Content Changes in [a] Biodiesel (B100) and [b] Biodiesel blends (B20)

The neat biodiesel used in this study had previously been stored more than one year after production, so at the beginning of the test, it was found the water content of the sample exceeds the limit specified standard of 500 ppm.

The greater changes in water content of B100 during storage time were occurred in glass tank, however in case of B20, the highest change was taken place in HDPE tank. The changes were measured up to $11.6 \%$. Some regression equations were also generated for evaluating the profile of water content of B20 during storage. It presented in Table 3.

Biodiesel has a polar chemical structure of carboxylate ester groups and presents the characteristics of absorbing more water than diesel. Thus, the addition of biodiesel to diesel increases the water retention capacity of the blend [20]. Meanwhile, humidity is one of important thing that affect in water content on fuel. In the period of this work, the relative humidity around location was $65-90 \%$.

Table 4. Projection maximum time for storing b20 under standard of water content

\begin{tabular}{|l|c|c|}
\hline Storage Type & Regression Equation & $\begin{array}{c}\text { Projection Storage } \\
\text { Time Limit [days] }\end{array}$ \\
\hline Glass Tank & $\mathrm{y}=1.7372 \mathrm{x}+264.61$ & 945 \\
\hline HDPE tank & $\mathrm{y}=2.2881 \mathrm{x}+266.1$ & 714 \\
\hline Steel Tank & $\mathrm{y}=1.0817 \mathrm{x}+265.75$ & 1519 \\
\hline
\end{tabular}

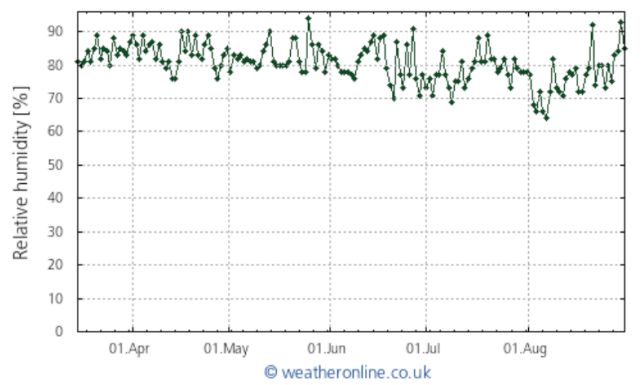

Fig 5. Relative Humidity on Storage Location (Palembang South Sumatera)

Source : http://www.weatheronline.co.uk, http://bmkg.go.id 
The higher the humidity the faster it will soak up water from the air. The measurement of relative humidity around location of the test is presented in Fig 5.

The source of the problem in HDPE tank may came from the access points. The tank access points (e.g., man-ways, fill tube, nozzles and fittings) are used for tank access and for critical operations conducted while the tank is static or being filled or emptied. These openings allow for the movement of humid air and for ingress of contaminants resulting in product quality degradation. Humid air that enters fuel tanks during normal temperature cycling (breathing) can over time result in water condensation in the tank when the ambient temperature reaches the dew point. It can be more of a problem in higher humidity regions.

Based on physico-chemical analysis, the steel storage tank peforming the minimum changes in fuel properties. It seems more secure for storing biodiesel blends, rather than HDPE and glass tank. Steel tank is provenly solid, strong, and opaque. It can protect fuel from sunlight exposure. Otherwise, it generally has heavy weight, more complex construction and higher maintenance cost. As like other metals, steel is a good conductor, so it possible to transfer heat by temperature elevation on storage. Storage in condition with higher temperature can accelerate oxidation. At a certain condition of storage and or higher temperature, the oxidation process begins with an initial chain reaction when highly active free radicals are formed by the influence of heat, light, air, or metal ions [2]. A comparative analysis of the various tank materials indicates that steel remains a costeffective material that meets all of the required performance criteria. In spite of that, a physical aging of biodiesel stored in steel tank may be still problematic. Polymers has become leading materials for various applications, including storage. It can be both thermal and electrical insulators. Generally, polymers are very light in weight with significant degrees of strength.

As resulted from this research, the placement of the storage tanks indoor was not extremely reducing oxidation or degradation effects. The light exposure in relatively long sunhours period per day and contact with humid air was major cause of the problem. It happened in all kind of storage tanks materials, including steel tank. The worst effect was happened in HDPE tank. The interaction of fuel with HDPE tank material was objected in several studies by many authors. The petroleum diesel was found to cause higher weight gain in the HDPE, that is, swelling, than the biodiesel [18]. Otherwise, the glass container provided the best protection to oil samples as indicated by the best sensory properties, followed by plastic and tinplate containers [21]. Metals tanks had the highest values of sedimentation after specified period of storage [22].

Glass storage tank seems not popular for fuel storage but some test led to some new findings. As like other polymeric materials, glass is inert to the corrosive environments inside and outside the tank. It acts as an insulator to retard heat transfer to the fuel. It can also be properly designed and installed to control any contact with humid air and can be produced with a resin with dark surface to protect from light exposure.

Fuel must be store in a moisture-free location away from heat and out of direct sunlight. If unable to store out of direct sunlight or warm weather; cover tanks with reflective tarp. To reduce fuel polymerization and oxidation, store in tightly sealed full tanks.

Glass tank is become attractive for those requirements. As known, oxidation is an irreversible reaction. It is a one-way path to the demise of the materials of storage. Meanwhile, physical aging of any fuel is reversible. As stated by [23], if the material that has undergone physical aging is raised to a temperature above the glass transition and then rapidly quenched, the effects of aging that have occurred previously are erased regardless of the time frame over which they have occurred. This condition will facilitate a better maintenance process that hardly handled in steel tank and HDPE tank.

\section{Conclusion}

Biodiesel and its blend can be stored for more than 12 weeks in metal or polymeric tanks, and it physicochemically changed but still met the standard specifications. In a storage of B20, it is found a different patterns of changes in physical properties, such as density, viscosity and water content. The density and viscosity B20 was increased slightly during storage period. This condition was contributed by temperature around the tanks and oxigen and daylight exposure in the area of the storage. The water content of B20 was found increased significantly. The greatest changes in water content was happened in B20 stored in HDPE tank. It is due to high relative humidity that triggering oxidation and degradation in biodiesel blends.

The changes in physical properties of B20 are not only originating caused by the molecular structure, but it is very sensitive to environmental factors such as temperature, humidity, exposure to daylight or sun. Moreover, the tank configuration (roof design and access points) are very influential in the storage stability of biodiesel blends.

The selection of storage materials for biodiesel blends is necessary to consider the resistence effect on oxidation, degradation and corrosion. The material of storage tank must be able to inhibit any cause to oxidation, such as the increase of storage temperature, protect from sunlight exposure and contact with humid air. Glass tank is found better among other polimeric materials for storing biodiesel, due to its chemical resistance, and flexibility designed for controlling air access points. It can be modified in design to set in dark surface in order to protect from light exposure.

\section{References}

1. M. Shahabuddin, , M. Kalam, H. Masjuki, M. Bhuiya, M. Mofijur, Energy, 6, 616-622 (2012) 
2. P. Udomsap, N. Chollacoop, T Subongkoj, T. Hirotsu, Int. J. Renewable Energy, 4 (2), 47-59 (2009)

3. P. Mazumdar, V. B. Borugadda, V. V. Goud, (2013). Int. J on Environmental Engineering 3. 13 (2013)

4. H. Yusof, N Tamaldin, M. Abdollah, A. Khalid, ARPN J. of Engineering and Applied Sciences, 10 (17) 7707-7711 (2015)

5. H. Meenakshi, A. Anand, R. Shyamala, R. Saratha, Chemical Science Transactions 2, 99-104 (2013)

6. J. Czarnocka, M. Odziemkowska, CHEMIK, 69 (11) 771-776 (2015)

7. A. Khalid, N. Tamaldin, M. Jaat, M. Ali, B. Manshoor, I. Zaman, Procedia Engineering, 68, 225230 (2013)

8. H. Yusof, N. Tamaldin, G. Omar, M.F. Abdollah, Int. $J$. of Education and Learning Systems, 1, 129-134 (2016)

9. C. Ezeanyanaso, V. Ajibola, E. Agbaji, E. Okonkwo, O. Okunola, Y. Alhassan, Greener Journal of Agricultural Sciences , 2, 195-206 (2012).

10. Y.P. Wu, Y.F Lin, J. Y. Ye, Biodiesel - Quality, Emissions and By-Products. 71-88 (2011)

11. S. Kovacs, G. Polczmann, J Hancsok, Hungarian J. Indistrial Chemistry Veszprem. 39.(3). 369-373 (2011)

12. H. Zakaria, A Halid, M. Farid, Applied Mechanics and Materials 465-466, 316-321 (2014)
13. M. Ramos, C. Fernandez, A. Casas, L. Rodriguez, A. Perez, Bioresource Technology, 100, 261-268 (2009)

14. ASTM. Standard Specification for Biodiesel Fuel (B100) Blend Stock for Distillate Fuels.1131-1136 (2009)

15. E. R. Mat, W.W. Yuhaidi, M. Kamaruddin, O. Hassan, J. Advanced Research in Fluid Mechanics and Thermal Sciences, 2 (1), 8-12 (2014)

16. Christensen, R. L. McCormick, Fuel Processing Technology 128, 339-348 (2014)

17. M.A. Ortega, G.M. Alpírez, A. Eliezer, C.G. González, FORMATEX, 279-289 (2013)

18. E. Torsner, Corrosion Engineering, Science and Technology. 45:42 (2010)

19. G. Knothe, Fuel Processing Technology 88 669-677 (2007)

20. P. B. L. Fregolente, Wolf Maciel , L. S. Oliveira' Braz. J. Chem. Eng. 32 (2015)

21. M. Rababah, H.Feng, W. Yang, K. Eriefej, M. A1Omoush. Int J Agriculture \& Biology Engineering 4 66-72 (2011)

22. L. Díaz-Ballote, A. Castillo-Atoche, L. Maldonado, M.A. Ruiz-Gómez, E. Hernández, Journal of Physics D: Applied Physics, 4935 (2016)

23. M. Sepe LLC, Plastics Technology, December (2014)

Corresponding author: leilynurul@unsri.ac.id 